\title{
HISTÓRIA E CRISTIANISMO: A NARRATIVA HISTÓRICA
}

\author{
History and christianity: the historical narrative
}

Nara Lívia Timbó de Oliveira ${ }^{1}$

RESUMO: O presente trabalho busca expor, de acordo com o que Nietzsche elabora em seu escrito de 1862, Fatum e História, o carácter estranhado na relação entre história e vida humana na modernidade. Tal caráter remete às compreensões partidárias acerca da história, as quais reenviam ao afastamento do homem da vida. Esse afastamento reenvia a certos hábitos e preconceitos, que são baseados em uma determinada compreensão da história, incutido aos homens modernos desde a infância. A compreensão vigente na modernidade é a visão histórica do cristianismo, onde a especulação acerca da história é envolta na moral. Esse olhar moralizante, para Nietzsche, conduz a especulações estéreis que ameaçam ameaça a vida humana, limitando a vontade individual e impondo aos povos uma forma de vida uniforme. De acordo com o pensamento nietzscheano, para que a vida humana não perca seu caráter criador, é preciso romper com o cristianismo e construir uma interpretação histórica livre de preconceitos morais cristãos.

Palavras-chave: História. Cristianismo. Moral.

\begin{abstract}
The present work seeks to expose, according to what Nietzsche elaborates in his writing of 1862, Destiny and History, the strange feature in the relationship between history and human life in modern times. This feature refers to tainted understandings about history, which refer to the removal of man from life. This removal refers to certain habits and prejudices, which are based on a certain understanding of history, instilled in modern men since childhood. Modernity's current understanding is the historical view of Christianity, where speculation about history is shrouded in morals. This moralizing look, for Nietzsche, leads to sterile speculations that threaten human life, limiting individual will and imposing a uniform way of life on peoples. According to Nietzschean thought, it is necessary to break with Christianity and build a historical interpretation free of Christian moral prejudices so that human life does not lose its creative character.
\end{abstract}

Keywords: History. Christianity. Moral.

\footnotetext{
${ }^{1}$ Bacharel em Filosofia pela Universidade Estadual do Ceará (UECE). E-mail: nliviatimbo@gmail.com
} 


\section{INTRODUÇÃO}

Fatum e história (2005) é o primeiro ensaio histórico-filosófico de Nietzsche. O filósofo o escreveu quando tinha apenas dezessete anos, durante as férias de 1862, como parte das obrigações da sociedade em que fundou. Apesar do ensaio não ser comumente debatido, ele é relevante, pois, segundo Beytía, há aspectos que tornam este ensaio importante para a compreensão do pensamento do filósofo:

É relevante, nesse sentido, considerar a frase de Elizabeth Nietzsche (1912: 27), que, referindo-se ao seu irmão, disse: "nada nos ensina mais sobre sua evolução intelectual do que seus ensaios e relatórios para a Alemanha". Dado que metade dessas contribuições foram composições musicais ou sobre música (Love, 1966), este ensaio se destaca imediatamente por seu tema distinto: os fundamentos interpretativos da história e da ação humana² (BEYTÍA, 2016, p. 282, tradução nossa).

Nesse sentido, Fatum e história é um escrito importante para compreender o desenvolvimento dos principais temas pensados pelo filósofo ao longo da sua trajetória filosófica. Safranski e outros intérpretes contemporâneos compreendem que "este texto como uma 'primeira tentativa com a filosofia', mas sem aprofundamento na globalidade do sistema teórico proposto lá por Nietzsche ou na profundidade dos argumentos desenvolvidos [posteriormente]"3 (BEYTÍA, 2016, p. 284, tradução nossa).

Neste trabalho, utilizaremos Fatum e história, dando ênfase nos fundamentos imperativos da história que, para Nietzsche, reenviam ao Cristianismo. Discorreremos sobre como a narrativa cristã sobre a história conduz os homens a certa limitação das possibilidades criadoras da vida, chamadas de especulações estéreis, além de apontar quais vias o filósofo sugere para enfrentar a ameaça que o cristianismo representa na vida humana.

\section{FATUME HISTÓRIA: ESPECULAÇÕES ESTÉREIS E CRISTIANISMO}

\footnotetext{
${ }^{2}$ No original: "Es relevante, al respecto, considerar la sentencia de Elizabeth Nietzsche (1912: 27), quien, refiriéndose a su hermano, señaló: "nada nos enseña más sobre su evolución intelectual como sus ensayos y reportes escritos para Germania". Dado que la mitad de dichas contribuciones fueron composiciones musicales o sobre música (Love, 1966), inmediatamente destaca este ensayo por su distintiva temática: los fundamentos interpretativos de la historia y la acción humana".

${ }^{3}$ No original: "Este texto como una 'primera tentativa con la filosofía', pero no han indagado en la globalidad del sistema teórico propuesto allí por Nietzsche ni en la profundidad de los argumentos desarrollados".
} 
Para Nietzsche, a história não é contada e julgada de um ponto de vista mais livre de valores, e isso diz respeito a influência do cristianismo na vida dos homens. Devido aos hábitos e preconceitos cristãos incutido aos homens desde a infância, eles acreditam serem obrigados a considerar uma única construção de narrativa história. Toda interpretação dela que possui caráter não partidário e que seja de acordo com a época ${ }^{4}$ é compreendido como delito.

Esta narrativa histórica que se põe como única é fruto daquilo que Nietzsche denomina por extravio em especulações estéreis. Tais especulações são originadas de um espírito cujo desenvolvimento da vida foi submerso aos preconceitos históricos. As consequências deste extravio não se reduzem à interpretação da história, mas a todos os aspectos da vida humana, já que a influência do cristianismo interfere nas ações e pensamentos dos homens.

Na cultura vigente do período do filósofo, os hábitos e preconceitos são parte fundamental do desenvolvimento dos indivíduos e da humanidade. Tudo aquilo que é produzido na modernidade, desde as relações sociais até as ciências, tem como pressuposto estes elementos culturais; no caso, elementos da moralidade cristã.

A doutrina do cristianismo, presente em todas as instâncias da vida humana, conduz a certo julgamento. Desde criança os homens perdem sua fé infantil ${ }^{5}$ por assimilarem que, tanto em pensamento quanto em ação, só é correto considerar a via do pensamento cristã. A impossibilidade de pensar algo distinto das especulações estéreis postas pelo cristianismo caracteriza, segundo o filósofo, a negação das possibilidades criadoras ${ }^{6}$.

Nesse contexto, onde tudo o que é desenvolvido tem pressupostos que levam a ter como resultado meras especulações estéreis, que não possibilitam a vida criadora, a ciência filosófica também pressupõe elementos cristãos. Acerca disto, Nietzsche comenta: "Quantas vezes nos pareceu ser toda a nossa filosofia uma torre babilônica: alçar-se até o céu é o objetivo de todos os

\footnotetext{
${ }^{4}$ Desde a juventude, Nietzsche compreende que há valores que não se sustentam em seu tempo presente, mas que permanecem por meio de hábitos e preconceitos. A moral é identificada como esse elemento de permanência de costumes de outro período no presente. Esta compreensão entre valores e moralidade, no entanto, é mais bem desenvolvida pelo filósofo em seu período de maturidade (cf. NIETZSCHE, 1998, 6, p. 5556).

${ }^{5}$ Nietzsche não especifica o que é tal fé, mas podemos pensar em algo que remeta a uma via mais livre de interpretação do mundo que, ao longo da formação do indivíduo, é posto como delito.

${ }^{6}$ Em seu escrito Sobre a utilidade e a desvantagem da história para a vida, Nietzsche desenvolve o conceito de doença histórica para pensar acerca da impossibilidade de criação de vida devido aos excessos do historicismo (v. NIETZSCHE, 2014, p. 141). Tal conceito tem relação com o cristianismo e com o pensamento filosófico vigente da época, a saber, de Hegel. No entanto não nos aprofundaremos nesse conceito neste trabalho.
} 
grandes esforços; o reino dos céus na terra significa praticamente a mesma coisa" (NIETZSCHE, 2005, p. 59-60).

O método da ciência filosófica adotado pela tradição cai em especulações estéreis, pois seu procedimento, ao seguir a ótica do pensamento cristão, afasta o homem das suas questões em prol de algo mais elevado. Esta relação de proximidade entre filosofia e pensamento divino traz, segundo o filósofo, triste resultado para a humanidade. Tal resultado é uma infinita confusão de ideias, onde a má compreensão das conjecturas que sustentam o cristianismo. Tais conjecturas, tal como a existência de Deus e a autoridade da Bíblia, aparentam ser verdades inquestionáveis, devido a sua persistência ao longo do desenvolvimento da humanidade. Acerca disto, Sobrinho (2005, p. 11) comenta:

Contudo, se era verdade que o cristianismo se fundava em preconceitos arraigados - como Deus, alma imortal, Juízo Final etc. -, preconceitos que a filosofia transformara em categorias informativas inclusive de análise histórica, por outro lado, não era menos verdade que estes preconceitos não podiam ser abolidos pela razão ou pela vontade.

\section{POR UMA VIA DE INTERPRETAÇÃO LIVRE DO CRISTIANISMO}

Diante desta confusão de ideias decorrente destas especulações estéreis, Nietzsche busca negar todo o fundamento desta história cultural. O filósofo também pretende edificar uma percepção distinta de história. Tal tarefa, no entanto, não pode ser realizada de modo instantâneo. Há um processo que possibilita a construção de interpretações históricas livres de preconceito. Acerca disto, Nietzsche (2005, p. 60) comenta:

O poder do hábito, a necessidade de algo superior, a ruptura com tudo que se encontra estabelecido, a dissolução de todas as formas sociais, a dúvida sobre se a durante dois milênios a humanidade não se teria deixado extraviar por uma falsa imagem, o sentimento da própria ousadia e temeridade inegociáveis: tudo isso mantém uma luta não resolvida, até que finalmente uma série de experiências dolorosas, de acontecimentos tristes no nosso coração, nos levam novamente à velha fé infantil. De qualquer maneira, observar a impressão que estas dúvidas causam sobre o ânimo deve ser, para cada um, um marco importante da sua própria história cultural.

Para que os homens possam construir sua interpretação histórica livres de quaisquer preconceitos do cristianismo, é preciso, em primeiro lugar, uma série de experiências pessoais de confronto entre a história e a narrativa histórica única que marcam a história cultural de cada 
indivíduo, fazendo-o retornar a fé infantil. Tais lutas evidenciam que os conhecimentos advindos de especulações estéreis se baseiam em mero sentimento moral.

Segundo Nietzsche, a moral "é a soma de todas as verdades do nosso mundo" (NIETZSCHE, 2005, p. 61), onde estas, na modernidade, são interpretação que o cristianismo formula acerca história da humanidade. Por meio da luta do indivíduo com a narrativa única cristã, é possível compreender que os conhecimentos incutidos aos homens desde a infância não possuem metodologia apartidária. Para que a construção das narrativas históricas não caia em meras especulações estéreis, é preciso uma base metodológica distinta: a história e as ciências naturais (NIETZSCHE, 2005, p. 59).

\section{CONCLUSÃO}

A busca de Nietzsche é, portanto, para a possibilidade de cada indivíduo construa sua verdade sobre o mundo, sua moral, por meio da interpretação histórica livre ótica da moral cristã. Nesse sentido, tal busca é fundamentalmente sobre a emancipação do cristianismo incutidos aos homens desde a infância.

A ruptura com cristianismo incutido na humanidade que Nietzsche busca pode ser realizada após experiências de confronto entre história e narrativas. O filósofo pensa, no entanto, que "uma tentativa deste tipo não pode ser obra de algumas semanas, mas de uma vida inteira" (NIETZSCHE, 2005, p. 59).

Diante desse plano de construção de narrativa histórica, que só é possível após a realização da derrubada dos preconceitos incutidos no espírito dos homens, Nietzsche vislumbra como consequência novos resultados para a história da humanidade. Para ele, pensar a história pela ótica da história pode trazer verdades que possibilitem a verdade universal, ou seja, uma verdade que não pressupõe qualquer partido. As consequências deste modo de pensar fundamentam-se na própria história e nas ciências naturais.

\section{BIBLIOGRAFIA}

BEYTÍA, Pablo. Fatum e historia: la teoría de la acción esbozada por Nietzsche en su juventud. Andiamos, México, v. 13, n. 32, p. 281-304, 2016. Disponível em: < https://andamios.uacm.edu.mx/index.php/andamios/article/view/533/881>. Acesso em: 28 nov. 2018. 
NIETZSCHE, Friedrich. Fatum e História. In: SOBRINHO, Noéli Correia de Melo (org.). Escritos sobre história. São Paulo: Edições Loyola, p. 59-66, 2005.

. Genealogia da moral. São Paulo: Companhia das Letras, 1998.

Sobre a utilidade e a desvantagem da história para a vida. São Paulo: Hedra, 2014.

SOBRINHO, Noéli Correia de Melo. Apresentação e comentário. In: NIETZSCHE, Friedrich. Escritos sobre história. São Paulo: Edições Loyola, p. 7-58, 2005. 